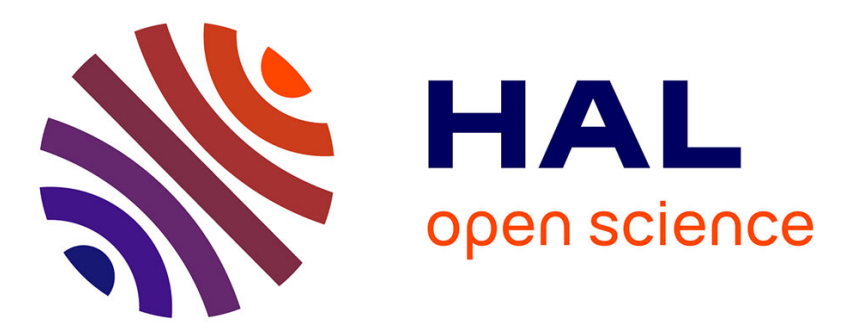

\title{
Accelerated snow melt in the Russian Caucasus mountains after the Saharan dust outbreak in March 2018
}

M Dumont, F. Tuzet, Simon Gascoin, G. Picard, S. Kutuzov, M. Lafaysse, B. Cluzet, R. Nheili, T. H Painter

\section{To cite this version:}

M Dumont, F. Tuzet, Simon Gascoin, G. Picard, S. Kutuzov, et al.. Accelerated snow melt in the Russian Caucasus mountains after the Saharan dust outbreak in March 2018. Journal of Geophysical Research: Earth Surface, In press, 125 (9), pp.1-13. 10.1029/2020JF005641 . hal-02937647

\section{HAL Id: hal-02937647 https://hal.science/hal-02937647}

Submitted on 14 Sep 2020

HAL is a multi-disciplinary open access archive for the deposit and dissemination of scientific research documents, whether they are published or not. The documents may come from teaching and research institutions in France or abroad, or from public or private research centers.
L'archive ouverte pluridisciplinaire HAL, est destinée au dépôt et à la diffusion de documents scientifiques de niveau recherche, publiés ou non, émanant des établissements d'enseignement et de recherche français ou étrangers, des laboratoires publics ou privés. 


\title{
Accelerated snow melt in the Russian Caucasus mountains after the Saharan dust outbreak in March 2018
}

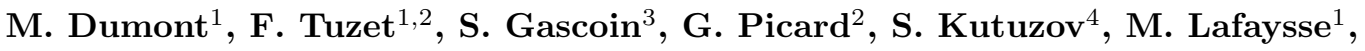 \\ B. Cluzet ${ }^{1}$, R. Nheili ${ }^{1}$, and T. H. Painter ${ }^{5}$ \\ ${ }^{1}$ Univ. Grenoble Alpes, Université de Toulouse, Météo-France, CNRS, CNRM, Centre d'Études de la \\ Neige, 38000 Grenoble, France \\ ${ }^{2}$ Université Grenoble Alpes, CNRS, IGE, 38000 Grenoble, France \\ ${ }^{3}$ CESBIO, Université de Toulouse, CNRS/CNES/IRD/INRA/UPS, Toulouse, France \\ ${ }^{4}$ Laboratory of Glaciology, Institute of Geography, Russian Academy of Science, Moscow, Russia \\ ${ }^{5}$ Jet Propulsion Laboratory/California Institute of Technology, Pasadena, CA, USA
}

\section{Key Points:}

- Dust from Sahara deposited on snow in Caucasus shortened the snow cover duration by 12 to 30 days.

- The impact of dust deposition was larger at higher elevation.

- Snow modeling uncertainties quantified by ensemble simulation strongly impact the estimated snow cover duration. 


\section{Abstract}

Light absorbing particles, such as mineral dust, are a potent climate forcing agent. Many snow-covered areas are subject to dust outbreak events originating from desert regions able to significantly decrease snow albedo. Here, using a combination of Sentinel-2 imagery, in situ measurements and ensemble detailed snowpack simulations, we study the impact on snow cover duration of a major dust deposition event that occurred in the Caucasus in March 2018. This is, to the best our knowledge, the first study using ensemble approach and Sentinel-2 imagery to quantify the impact of a dust event on the snow cover evolution. We demonstrate that the calculation of the impact is strongly affected by the snow model uncertainties but that the March 2018 dust event systematically shortened the snow cover duration in Western Caucasus. The shortening is higher for location with higher accumulation and higher elevation (median values of $23 \pm 7$ days) than for location at lower elevation (median values of $15 \pm 3$ days). This is because for sites with higher location and higher accumulation, melt occurs later in the season when more incoming solar energy is available. This highlights the huge impact of a single one-day event on snow cover duration, and consequently, on the hydrology of a large region.

\section{Introduction}

Light absorbing particles (LAPs) such as mineral dust or black carbon (BC) darken the snow surface and trigger several snow albedo feedbacks. LAPs are acknowledged as an highly efficient climate forcing [Skiles et al., 2018]. Although mineral dust, hereafter referred as dust, has received less attention than BC due to its lower absorption efficiency and natural origin, dust in snow is also an important driver of snowpack evolution [e.g. Painter et al., 2012; Dumont et al., 2014; Ginot et al., 2014; Skiles et al., 2018]. Dust deposition is generally more sporadic than BC deposition [e.g. Di Mauro et al., 2019] and dust optical properties largely vary with the source region [e.g. Caponi et al., 2017]. Presence of dust in snow is lowering the efficiency of darkening due to black carbon [e.g. Flanner, 2013]. Many snow covered regions frequently undergo major dust outbreaks leading to deposition of a large mass of dust on the snowpack which significantly decreases the snow albedo by several percent [e.g. Di Mauro et al., 2015], thus largely affecting the snow cover evolution until the complete melt of snow. For instance, in the Rocky Mountains, USA, episodic springtime depositions of dust may have led to a shortening of the snow cover duration by up to 51 days [Skiles and Painter, 2018]. In the European Alps, 
Di Mauro et al. [2019] showed that Saharan dust deposition advanced the snow meltout date by 38 days. Such changes in duration of the snow cover in mountain areas impact the hydrology, glacier mass balance, permafrost, as well as ecological and socioeconomic systems [Painter et al., 2010; Blankinship et al., 2014; Beniston et al., 2018].

The long range transport and deposition of dust from the deserts of the Sahara and Middle East to the eastern Mediterranean and the Caucasus mountains have been reported in a number of publications [Kokkalis et al., 2012; Kutuzov et al., 2013; Nastos et al., 2011; Shahgedanova et al., 2013]. Analysis of dust layers in ice cores showed that 4-7 dust deposition events occur in Caucasus every year during spring time and the strongest dust deposition events in this region are associated with the dust transport from northern Sahara [Kutuzov et al., 2013]. Saharan dust deposition is thus a natural and common process in this region of the world, and several studies have reported increasing trends in dust deposition [Skiles et al., 2018; Kutuzov et al., 2019]. Despite the growing corpus about the climatology and history of dust deposition events so far there was no published quantitative assessment of the impact of dust deposition on snow melting in this mountainous region. The present study aims at quantifying the impact of a single dust event deposition on the snow cover duration in this area.

A dust deposition event occurred in eastern Mediterranean, Anatolia and Caucasus on 22 and 23 March 2018 [Solomos et al., 2018; Marmureanu et al., 2019]. It was selected for our study case. The event was a record-breaking dust episode with dust concentration over Greece and Crete exceeding $6 \mathrm{mg} \mathrm{m}^{-3}$ [Marmureanu et al., 2019]. A dust storm started in the Libyan desert in the afternoon on 21 March uplifting a massive cloud of dust to the mid troposphere that moved over the island of Crete to the eastern Mediterranean [Roesli and Karvelis, 2018]. Initially dry air mass in Saharan depression was merged with the atmospheric front above the Black Sea and first precipitation were recorded over the Eastern Europe and Turkey (movie SI_1). A warm front reached the western Caucasus in the morning on 23 March when the dust was deposited during snowfall [Marmureanu et al., 2019]. The snow depth increased by $20 \mathrm{~cm}$ in 3 hours at the weather station at 1600 m a.s.l in Krasnaya Polyana (M3 in Fig. 1b). The deposition of mineral particles resulted in significant snow color change in the ski resorts, visible on standard photographs. The event was widely reported in the media and social media [e.g. Gascoin et al., 2018; Marmureanu et al., 2019]. This event was then buried by subsequent 
snowfalls. It nevertheless reappeared later due to melting, and accelerated the melt of the remaining snowpack.

To investigate the impact of this event on snow cover duration, we uses data from the Russian mountain resort Krasnaya Polyana, located in the Western Caucasus and including a cluster of ski resorts (Rosa Khutor, Alpika-Service, Gornaya Carousel, and Laura). The snow cover duration is usually relatively short (late December to March) due to mild winter temperatures and a negative trend in snow cover has been observed since the 1980's [Sokratov et al., 2014]. The duration of snow directly influences the economic sustainability of these low altitude ski resorts. In this study, we used the highresolution multi-spectral images from Sentinel-2 (S2) to quantify the temporal and spatial evolution of dust content in snow after this major dust outbreak. To estimate the shortening of the snow cover duration caused by this single event in this region, we combined S2 information with in situ snow depth measurements, atmospheric reanalysis and detailed ensemble snowpack simulations. We investigate the spatial variability of the shortening as a function of elevation and we quantify the uncertainty of our results.

\section{Materials and Methods}

\subsection{Study sites and in situ data}

The study site is located close to Krasnaya Polyana mountain resort in Russia (43.68N, 40.20E, Fig. $1 \mathrm{a}, \mathrm{b})$. The area covers $56 \mathrm{~km}^{2}$ and the elevation ranges from 700 to $2475 \mathrm{~m}$ a.s.l.. Within the area, snow depth was measured at 3 locations (M1, $2200 \mathrm{~m}$ a.s.l, M2, $1700 \mathrm{~m}$ a.s.l. and M3, $1600 \mathrm{~m}$ a.s.l.; Fig. 1b, where M is used for measurement site). These sites are located in small flat areas in the vicinity of the ski slopes at the Gornaya Karusel resort. Snow depth was manually measured as a part of the snow avalanche service duties using snow stakes at sites M1 and M2. At the M3 site, the snow depth was recorded by a sonic ranger (Campbell SR50) installed on the mast of an Automatic Weather Station. Note that for all the 3 sites, the area was not flat enough at the 10 meter scale to properly exploit S2 data.

Dust content in snow was measured on 27 March 2018 at location D (Rosa Pik, $2300 \mathrm{~m}$ a.s.l., D for dust site). Two samples were collected (300 $\mathrm{mL}$ each, $10 \mathrm{~cm}$ snow from the surface), then melted and filtered using $0.2 \mu \mathrm{m}$ pore size filters. The dust content, cal- 
culated from the weight of the dust particles on the filter, was 606 and 786 ppm respectively for the two samples. No snow depth measurement was available for site D.

Finally, to analyze the satellite signal avoiding uncertainties due to slopes, we selected a flat area far from any disturbance due to the ski resort (site F, Fig. 1b, F for flat site). The local slope, calculated from the SRTM DEM resampled at $20 \mathrm{~m}$ (native resolution $90 \mathrm{~m}$ ), over 4 pixels (at $20 \mathrm{~m}$ resolution) is $2 \pm 1$ degrees. No snow depth measurement is available for site $\mathrm{F}$.

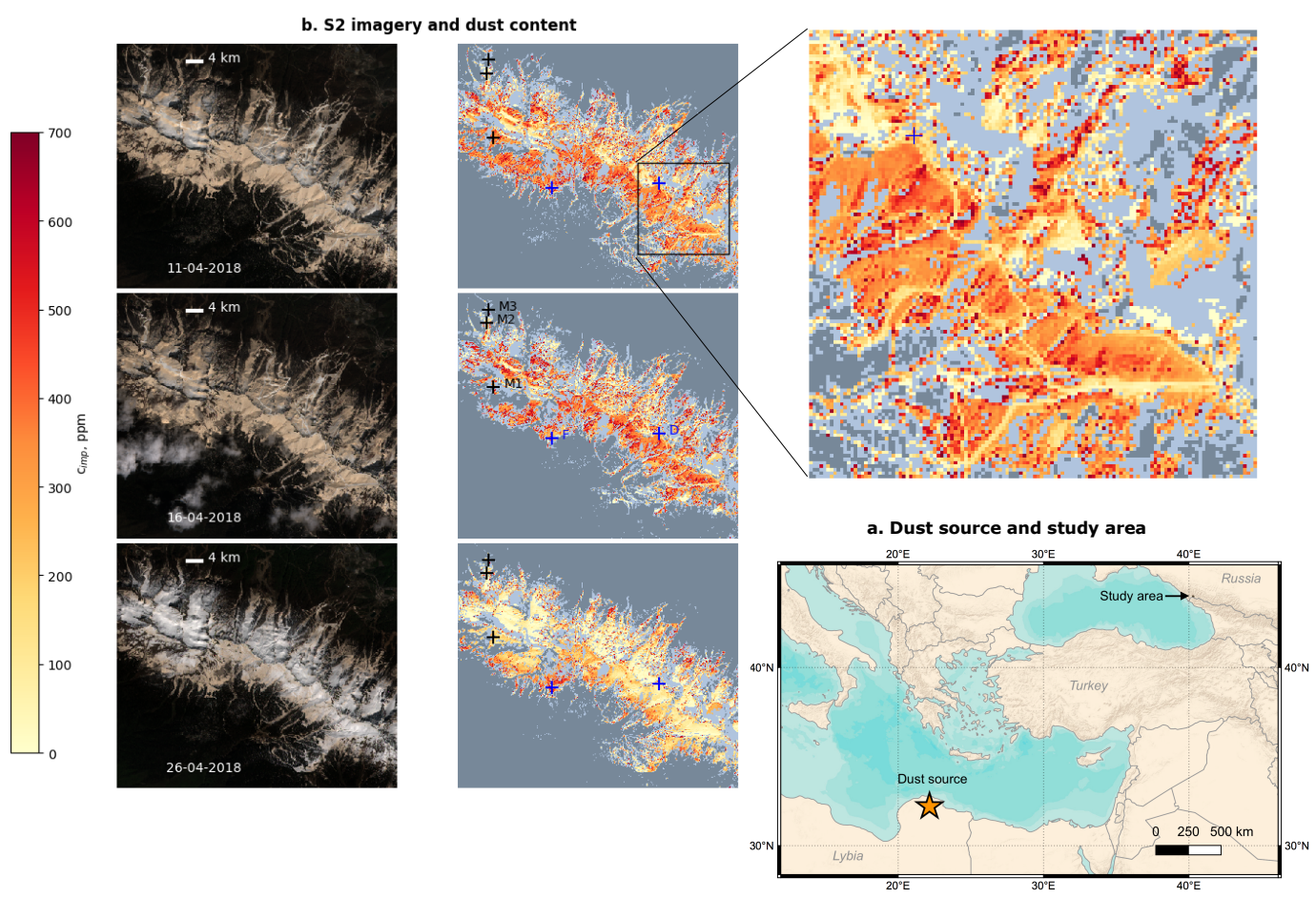

Figure 1. (a) Location of the study site and of the dust origin region, (b) S2 time series, left column RGB composite, right column, estimated dust content in ppm. Shaded areas are clouds or no snow (dark grey) or mixed, inclined or noisy pixels (light grey). The 4 locations correspond to snow depth measurement sites (M1, M2, M3), dust content measurement site (D) and a reference flat area $(\mathrm{F})$. On the top right, a zoom of the dust content maps is provided for the black rectangle. Cleaner ski slopes are visible on the map (see zoom).

\subsection{Sentinel-2 data and processing}

Sentinel-2 (S2) L2A surface reflectance images (not corrected for slope) were processed using MAJA algorithm as in Hagolle et al. [2017] (MACCS-ATCOR Joint Algo- 
rithm, where MACCS stands for the Multi-Temporal Atmospheric Correction and Cloud Screening software) and the snow masks were computed with the same algorithm as the Theia snow products [Gascoin et al., 2019]. Nine scenes, almost cloud-free, were selected after the dust event covering 1 April to 27 June 2018. In addition, we used the image acquired on 12 March 2018, before dust deposition and after a dust-free snowfall (Fig. 2a).
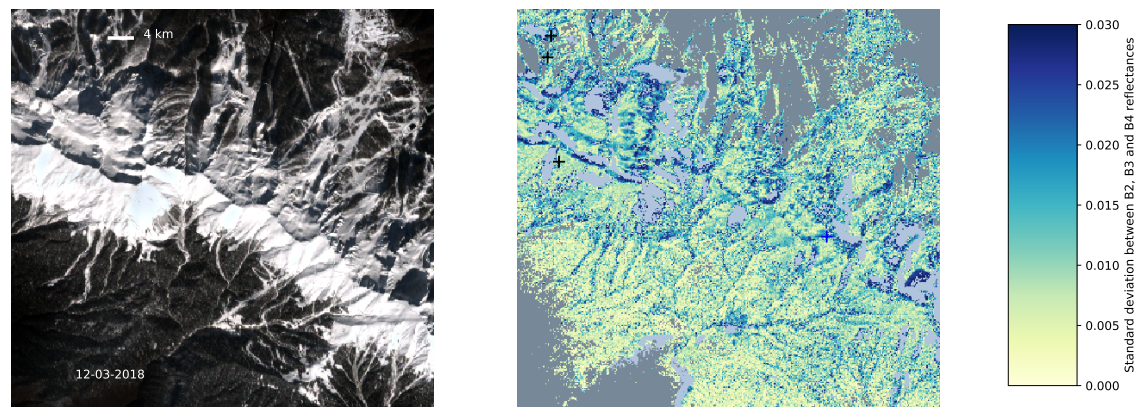

Figure 2. (a) RGB image of the study area for 12 March 2018 and (b) Standard deviation between reflectance in bands 2, 3 and 4 for 12 March 2018. Slopes above 40 degrees are masked out in light grey, pixels with NDSI lower than 0.4 are masked out (dark grey).

First, all spectral bands were downsampled to $20 \mathrm{~m}$ resolution using nearest neighbour interpolation to match the spatial resolution of the snow masks [Gascoin et al., 2019]. For every valid pixel, surface reflectance acquired at dates after the dust deposition was normalized by the surface reflectance acquired on 12 March 2018 in band 3 and band 2 (central wavelengths: 492 and $560 \mathrm{~nm}$ ) to mitigate topographic effects (local slope and aspect) on the measured reflectance in snow covered areas. For this, we assumed that the intrinsic surface reflectance on 12 March was spatially uniform for clean fresh snow and that the deviation of the recorded value was mainly due to change in local geometry of illumination and re-illumination and shadowing [e.g. Dumont et al., 2017] and that this topographic effect was almost the same for all dates. This assumption implies that the snow surface LAP content was very low for all locations. Since the image on 12 March was taken less than 24 hours after the snowfall and that the new snow amount varied between 20 and $40 \mathrm{~cm}$ for the measurement sites, we believe that this assumption is reasonable. 
Prior to the estimation of the dust content, any pixel considered as cloud or snowfree was masked out, using the S2 snow mask from MAJA. Mixed pixels (NDSI smaller than 0.7 - approximately corresponding to the threshold for $100 \%$ snow cover in Salomonson and Appel [2004]), steep pixels (slope greater than 40 degrees - where topographic effects require a detailed correction as explained in Picard et al. [2020]) and noisy pixels on 12 March (standard deviation between reflectances in the visible bands 2, 3 and 4 greater than 0.03, i.e. higher than the minimum errors in retrieved reflectance, Kokhanovsky et al. [2019]) were also discarded from the calculation (Fig. 2b).

The dust content, $c_{\mathrm{dust}, i}$, was estimated for date $t$ from band $i(i=2,3)$ surface reflectance in the visible range, $r_{i}$, and surface reflectance in the near-infrared range, $r_{8}$ (band 8: $842 \mathrm{~nm}$ ), using the following equation where $t_{0}$ is 12 March 2018 :

$$
\eta_{i}(t)=\frac{\log \left(r_{i}(t) / r_{i}\left(t_{0}\right)\right)}{\log \left(r_{8}(t) / r_{i}\left(t_{0}\right)\right)}, c_{\mathrm{dust}, i}=f_{i}\left(\eta_{i}(t)\right)
$$

Such ratio is only weakly dependent on snow specific surface area (SSA) and illumination geometry [e.g. Dumont et al., 2014; Kokhanovsky et al., 2018] (Fig. 3), enabling to separate the effect of dust and SSA on surface reflectance. Such ratio requires the use of two bands : one band sensitive to SSA and impurity content (visible range) and one band almost insensitive to impurity content (near-infrared range). The index in this study was based on $10 \mathrm{~m}$ resolution spectral bands from Sentinel-2. Consequently, we selected band 2 and band 3 in the visible range (band $4-665 \mathrm{~nm}$ being less sensitive to impurity content) and band 8 in the near-infrared range. Simpler indices such as in Dumont et al. [2014]; Di Mauro et al. [2017]; Huovinen et al. [2018] are sensitive to sun illumination angle and consequently to topography and dates. Such indices need to be applied to equivalent diffuse reflectance to reach high accuracy [e.g. Di Mauro et al., 2017]. Diffuse reflectance is not available from Sentinel-2. Thus the index in Eq. 1 includes a normalization, enabling a very weak dependence to illumination geometry (Fig. 3).The normalization is made possible since S2 has a constant view angle and a short revisit time. When the time span between the pre and post event images is only a few days then the sun geometry and viewing geometry can be considered identical.

The functions $f_{i}$ are five degree polynomials. The polynomials were obtained by performing a fit on $\eta_{i}$ values simulated with the snow radiative transfer model TARTES [Libois et al., 2013]. Namely, we obtained $\approx 8600 \eta_{i}$ values from TARTES simulations for each band with varying dust content (0-800 ppm), SSA (5 to $\left.60 \mathrm{~m}^{2} \mathrm{~kg}^{-1}\right)$ and illu- 
mination geometry (diffuse, direct illumination at 0 and 70 degrees) and a five degree polynomial was fitted on these simulated $e t a_{i}$ values (fig. 3 . For all the simulations we used the spectral mass absorption efficiency (MAE) of " $\mathrm{PM}_{2.5}$ Libyan dust" from Caponi et al. [2017] best corresponding to the dust origin region [Marmureanu et al., 2019]. Marmureanu et al. [2019] performed a chemical analysis of dust sampled in Romania from the studied event and measure $\mathrm{Fe} / \mathrm{Ca}$ ratio of 1.17 , very close to the 1.19 for $\mathrm{PM}_{2.5}$ Libyan dust in Caponi et al. [2017]. Using the data from Marmureanu et al. [2019] and eq. 4 in Caponi et al. [2017], the estimated fractional mass element ratio of iron, MFe, was $6.9 \%$. Note that no Mn measurement was provided in Marmureanu et al. [2019], which may lead to an overestimation of MFe. In Caponi et al. [2017], MFe is close, $5.2 \%$ for $\mathrm{PM}_{2.5}$ Libyan dust. Since MFe is controlling a large part of the absorption efficiency [Caponi et al., 2017; Moosmuller et al., 2012], $\mathrm{PM}_{2.5}$ Libyan dust from Caponi et al. [2017] was thus close in terms of optical properties to the dust deposited in the studied event. The simulated snow reflectance using Libyan PM2.5 from Caponi et al. [2017] was consistent with S2 surface reflectance spectra (Fig. 4). Note that as long as the spectral variations of the mass absorption efficiency are realistic, the exact value of the MAE does not affect the computed change in snow cover since the same MAE are used for S2 retrieval and in the snow model.

The estimation of dust content was done separately with band 2 and band 3 and the average was taken to yield the final dust content shown in Fig. 1b. Bands 2 and 3 have slightly different sensitivity to dust content and atmospheric and topographic corrections (Fig. 3). Nevertheless, the retrieved $c_{\text {dust }}$ were only slightly different in both bands (RMSE smaller than $60 \mathrm{ppm}$ ) which is an indication of the robustness of our estimation metod.

In this study, we choose to retrieve surface dust content and instead of the dust radiative effect as in Painter et al. [2012] in order to disentangle the effects of snow physical properties (surface SSA) and of dust content evolution on the radiative effect, and hence to separate the radiative effect of metamorphism versus to the radiative effect due to the enrichment in dust of the surface. 

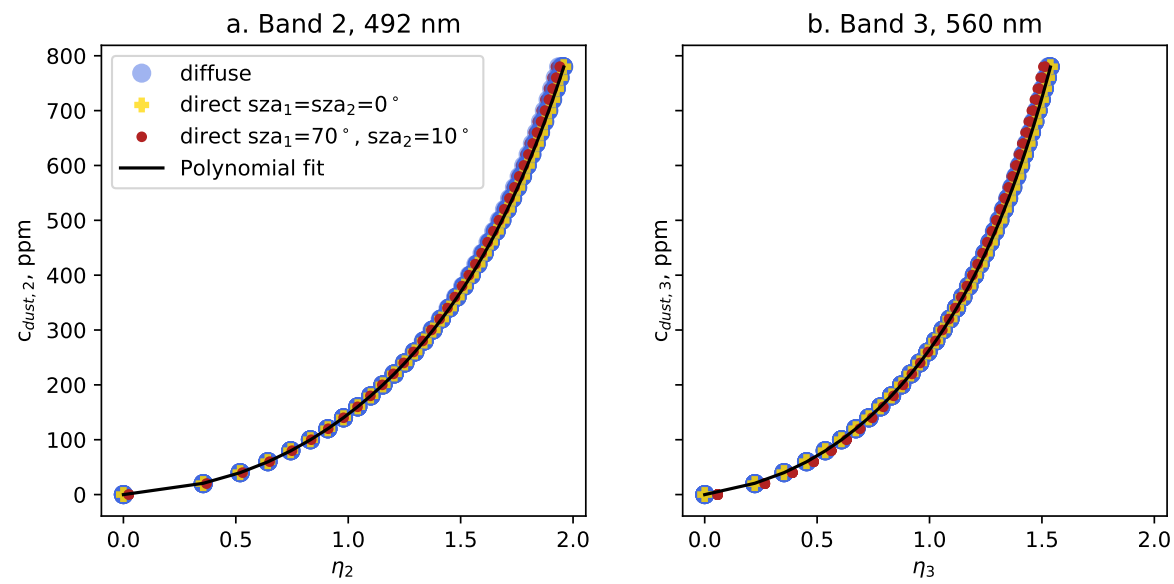

Figure 3. (a) Simulated dust content (ppm) as a function of reflectance ratio, $\eta$, in Eq. 1 for band 2. The markers (circles and crosses) correspond to TARTES simulations [Libois et al., 2013] using every possible pairs of SSA between 5 and $60 \mathrm{~m}^{2} \mathrm{~kg}^{-1}$ by step of $5 \mathrm{~m}^{2} \mathrm{~kg}^{-1}$. Snow at $t_{0}$ is supposed to be clean ( 0 ppm of dust). Blue dots are for diffuse reflectance (for both $t_{0}$ and $t$ ), yellow crosses are for direct nadir illumination for both $t_{0}$ and $t$ and red circles for direct illumination at 70 degree zenith angle for date $t_{0}$ and 10 degree zenith angle for date $t$. The polynomial fit obtained from the TARTES simulations is shown by the solid black line. (b) same as (a) but for band 3 .

\subsection{Snowpack simulations}

Snowpack simulations were performed using the detailed multilayer snowpack model SURFEX/Crocus [Vionnet et al., 2012], hereinafter Crocus, including an explicit representation of LAPs [Tuzet et al., 2017]. The model was used in its multiphysics ensemble configuration ESCROC [Lafaysse et al., 2017], with 35 members ensemble. The 35 members were selected to optimize the mean continuous ranked probability score on total snow depth on 10 diverse sites selected for the ESM-SnowMIP project [Krinner et al., 2018]. This gives good confidence on the ability of this ensemble to quantify snowpack modeling uncertainties. The model was run using dust with optical properties defined above and black carbon with optical properties as in Tuzet et al. [2017]. In addition, two adjustments were performed with respect to Tuzet et al. [2017]:

- Wet snow metamorphism law: to improve the agreement between simulated and observed SSA in the melt season (as observed in Tuzet et al. [2017], figure 4b), we 


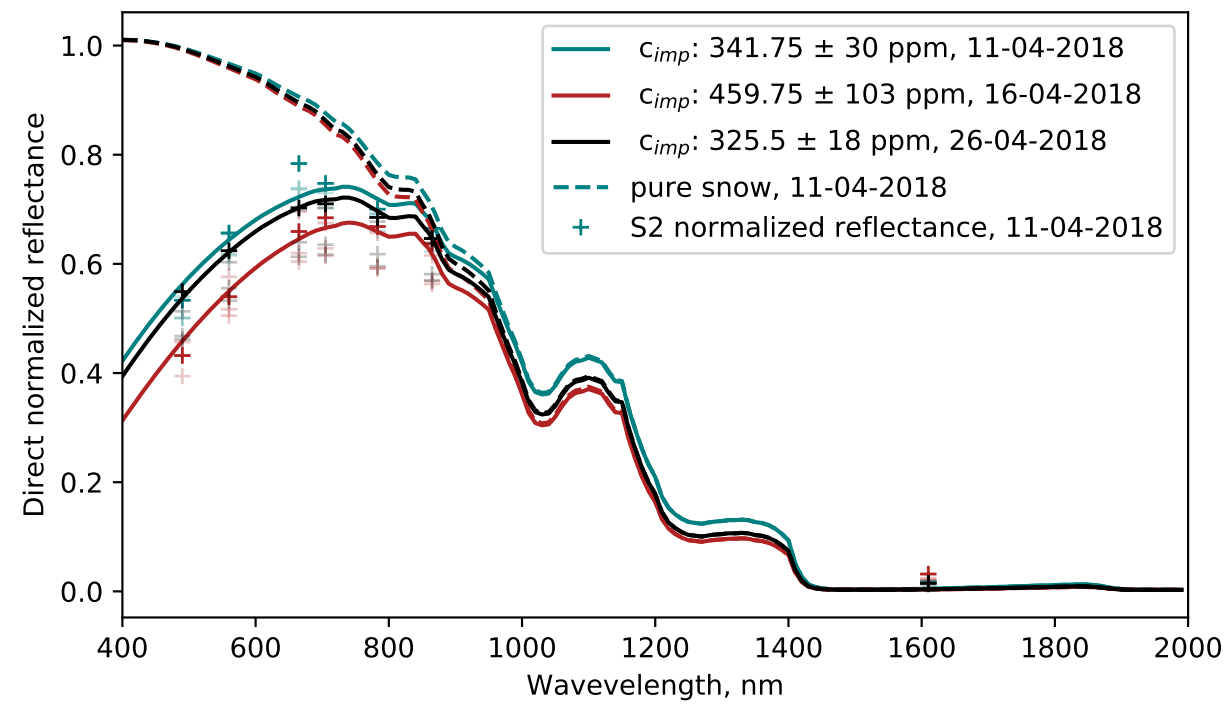

Figure 4. S2 estimated and modeled reflectances at site F (4 pixels at $20 \mathrm{~m}$ resolution, mean slope of 2 degrees with 1 degree standard deviation). The crosses correspond to S2 normalized reflectance (see methods), the solid lines to TARTES simulations with impurity content prescribed by S2 estimated content, dashed lines to pure snow simulations. The three different colors correspond to the dates. The transparent data correspond to the pixels values while the mean is indicated in opaque. S2 and TARTES reflectances are normalized by band 3 reflectance to mitigate topographic effect.

accelerated the law for metamorphism of wet snow from Brun et al. [1992] by increasing the wet volumetric growth by a factor of four. Such modification allowed a better agreement between optically measured SSA and simulated SSA presented in Tuzet et al. [2017] (Fig. SI_1).

- Surface LAP content: in case of partial melt of the surface layer, the dust content of the first numerical layer is increasing. When the layer is too thin, the model merges it with the lower layer usually leading to a decrease in surface dust content that is only a model artefact. This induces a spurious dependency of the surface dust content to the numerical layering. To avoid this artefact the LAP content of a melting uppermost layer was homogeneously distributed over the ten uppermost mm of SWE. 
To investigate the effect of LAPs content on snow evolution, three main simulation configurations were set-up : (i) pure snow simulation with no LAP ; (ii) baseline simulation with a constant deposition fluxes for dust (dry : $310^{-10} \mathrm{~g} \mathrm{~m}^{-2} \mathrm{~s}^{-1}$, wet : $310^{-9}$ $\mathrm{g} \mathrm{m}^{-2} \mathrm{~s}^{-1}$ ) and $\mathrm{BC}\left(\mathrm{dry}: 110^{-11} \mathrm{~g} \mathrm{~m}^{-2} \mathrm{~s}^{-1}\right.$, wet : $110^{-10} \mathrm{~g} \mathrm{~m}^{-2} \mathrm{~s}^{-1}$ ) ; (iii) dust $\times 1$ simulation, same as (ii) but with an additional wet deposition of $7.3 \mathrm{~g} \mathrm{~m}^{-2}$ of dust on 23 March. The dust mass deposits on the snowpack were chosen in the dust ${ }_{\times 1}$ scenario in order to reconcile the simulated dust content with in the dust content measured in situ. Baseline simulations are useful to quantify the impact of the dust event since the impact of such event is varying with the amount of other light absorbing particles usually present in the snowpack in the absence of a major dust outbreak event [e.g. Flanner, 2013]. In addition, to investigate the sensitivity of the snow cover evolution to the dust mass deposited during the event, four more simulations were performed, all iden-

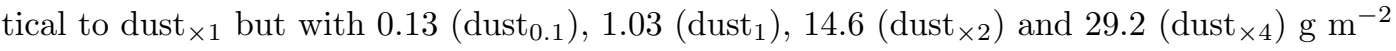
of dust on 23 March.

The model was forced using ERA-i meteorological reanalysis with an adaptation to the elevation of the location as in Dumont et al. [2014]; Mudryk et al. [2018]. Namely, ERA-i air temperature, specific humidity, downward longwave radiation and precipitation phase were adjusted using the difference in elevation between the simulation point and the ERA-i grid point. In addition, for locations M1, 2 and 3 and F, precipitation amounts were manually adjusted to fit measured snow depth before the dust event. The maximum modification performed for one precipitation event was $\pm 5.4 \mathrm{~kg} \mathrm{~m}^{2}$ (20\% for the total amount of this event). Shortwave radiation masking due to local topography was not taken into account in the simulations since the sites were located on open areas for which the masking had little impacts. Note that we did not include the uncertainties linked to the SW values in the simulations. In order to initialise the ground temperature, the simulations were initialised with a 3 year spin-up using adjusted ERA-i meteorological forcing and are then run from 1 June 2017 to 1 June 2018.

The daily surface radiative effect (SRE) due to LAP was calculated as the difference between the shortwave radiation absorbed by the snowpack in the simulations with LAPs and the pure snow simulations averaged over 24 hours. The daily SRE value includes the direct (snow darkening) and indirect (induced snow coarsening) radiative effect of the dust particles [Tuzet et al., 2017] and thus comprises feedback processes. Daily SRE was computed until $t_{\text {ground }}$ for each location, where $t_{\text {ground }}$ is defined as the first 
date at which one of the members of the ensemble had less than $50 \mathrm{~kg} \mathrm{~m}^{-2}$ of snow mass. SRE calculations were not performed later than $t_{\text {ground }}$ to ensure that SRE was not perturbed by solar energy absorption in the ground. The ground albedo was assumed constant over the solar spectrum and set to 0.2 . Note that the surface radiative effect is not radiative forcing as defined in the IPCC AR5 report [IPCC, 2013] since (i) SRE includes the effect of all dust and is not a difference with respect to pre-industrial era and since (ii) SRE is a difference in the energy absorbed at the surface and not a difference in the downward irradiance at the tropopause.

\section{Results}

\subsection{Temporal and spatial evolution of dust in snow}

Fig. 1b and Movie SI_2 display the temporal and spatial evolution of the dust content estimated from S2. The estimated dust content varied between 0 and 700 ppm according to the date and location. In Fig. 1b, the ski slopes on 11 and 16 April look cleaner than natural snow, probably due to grooming and artificial snow production (see zoom in Fig. 1b). The snow fall occurring between 16 and 26 April leads to cleaner snow on the image from 26 April. Fig. 4 shows the evolution of S2 surface reflectance at location F (4 pixels) for 3 dates in April. S2 reflectances were normalized by band 3 on 12 March and compared with surface reflectance simulated with TARTES (diffuse reflectance, lines). Dashed lines show pure snow simulations while solid lines show simulations with dust using the S2 estimated dust content as input. It shows that the agreement between S2 and the simulated reflectance is within 5\%. The simulated reflectance in band $11(1614 \mathrm{~nm})$ is slightly lower than the observed one. This may be attributed to dust scattering, that is not accounted for in TARTES and is known to increase the reflectance in this specific range of wavelengths for high dust content [Warren and Wiscombe, 1980].

For every date, the dust content spatial distribution features a gradient with elevation (Fig. SI_2a), larger dust content being generally found at lower elevation. This may be related to faster melt at lower elevation, leading to enrichment of the snow surface in dust [Sterle et al., 2013; Skiles et al., 2018]. The distribution of dust content with slope aspect displays larger dust content for south-west slopes for 16 April and 1 May (Fig. SI_2b). This may also be attributed to faster melt in south-west facing slopes. Another explanation could be that these slopes were exposed to the dominant wind dur- 
ing the dust outbreak thus accumulating more snow (and then more dust) than other slopes during the event.

\subsection{Shortening of the snow cover duration due to dust deposition}

Fig. 5 displays the simulated and measured snow depths for locations M1, M2, M3 and F (Fig. 1b). The ensemble median of three simulation set-ups (pure snow, baseline and dust $\left._{\times 1}\right)$ are reported in the plots. For the sake of clarity, only two ensemble envelops (baseline and dust $\times 1$ ) are shown in fig. 5. For locations M1, M2 and M3, the agreement between the measured and simulated snow depths is the best for dust $x_{\times 1}$ and dust $\times 2$ scenari (Tab. SI_1). The simulated melt-out date (median value of the dust $\times 1$ simulation) fits to within 2 days for each location to the in situ (M1, M2 and M3) and S2 (site F) measured melt-out date. S2 estimated dust content at location F and simulated dust content (dust ${ }_{\times 1}$ set-up) are in agreement for almost all dates (Fig. SI_3). The simulated dust content at site $\mathrm{F}$ (median ensemble value 600 ppm, ensemble values ranging between 680 and $780 \mathrm{ppm}$ ) also agrees reasonably with the measured dust content at site D just after the dust event (606 and $786 \mathrm{ppm}$ from the two measurements). This is not the case for the dust $\times 2$ scenario in which the dust content is twice higher than S2 dust content (Fig. SI_3, not shown).

Fig. 6 displays the difference in melt-out dates, $\Delta t_{\text {melt_out }}$, with respect to the pure snow configuration for the different locations and configurations. The shortening of the snow cover duration in the dust $x_{\times 1}$ configuration by location ranges from $15 \pm 3$ days (lower location, M3) to $23 \pm 7$ days (higher location, M1). The differences in melt-out date between baseline and pure snow simulations range within $1 \pm 2$ days, while the median differences in melt-out between the dust $x_{1}$ and dust $x_{4}$ simulations range between 3 and 8 days. The spread in $\Delta t_{\text {melt_out }}$ increases with elevation, peak SWE value and dust content. The box-plots of the baseline simulations are not overlapping with the box-plots from the three high dust scenario (dust $x_{\times 1}$, dust ${ }_{\times 2}$ and dust $_{\times 4}$ ), indicating that the shortening can be unambiguously attributed to the dust event regardless the uncertainty of the other parameterizations in the snowpack model. In addition, $\Delta t_{\text {melt_out }}$ sensitivity to the dust content is higher for low dust content (baseline, dust ${ }_{0.1}$ and dust ${ }_{1}$ ) than for higher dust content (dust $\times 1$, dust $\times 2$ and dust $_{\times 4}$ ) and increases with elevation. 
Lastly, Fig. 7 shows for each configuration the dependence of $\Delta t_{\text {melt_out }}$ on the date of melt-out in the pure snow simulations. It shows that for every location and configuration, there is a positive correlation between the two variables. In other words, the impact of LAP is stronger when the snowpack is melting later, most likely because solar irradiance is increasing as the days lengthen. The spread in the relationship is higher for the larger dust contents.
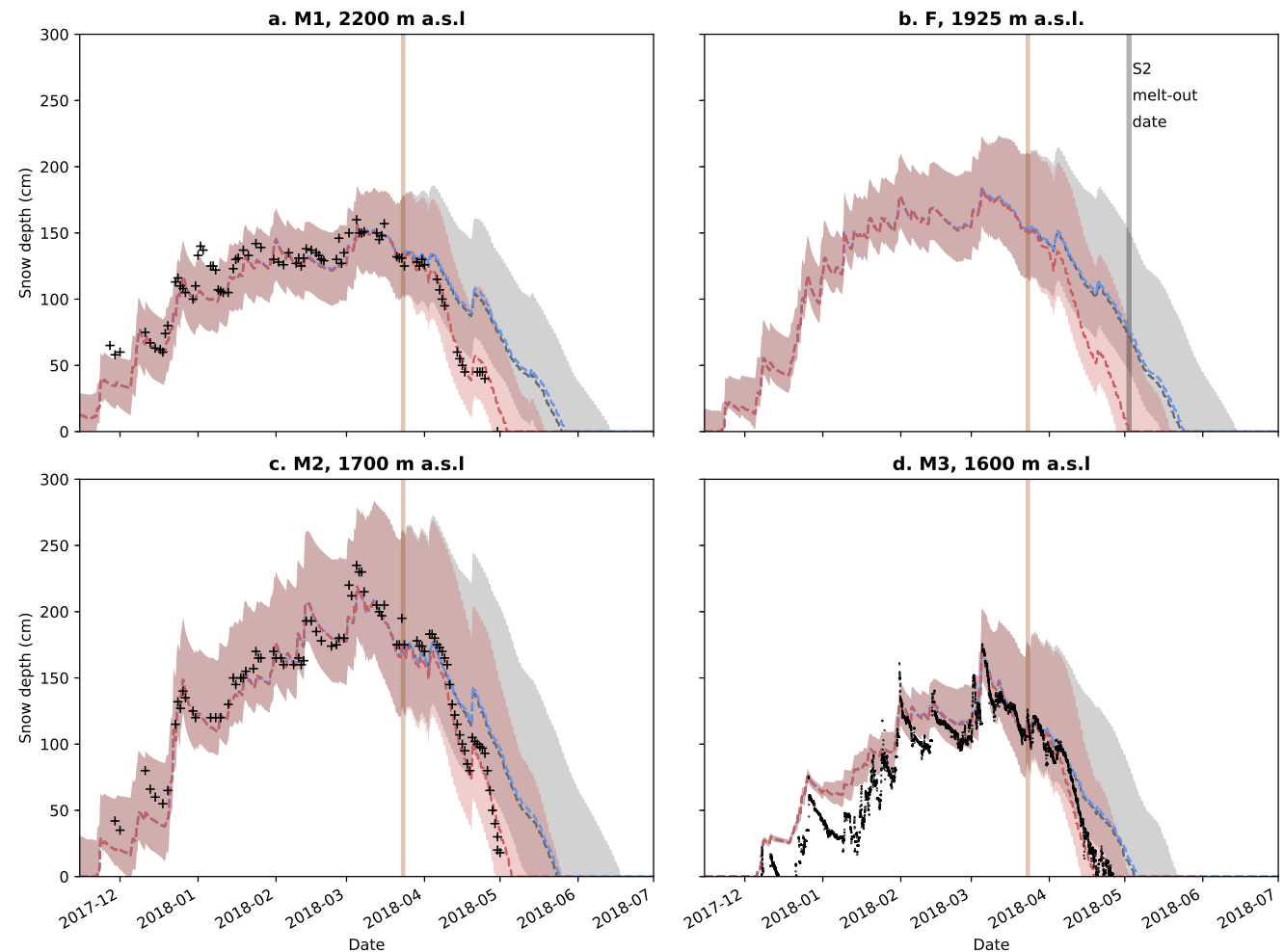

+ Manual measurements --- Pure snow median --- Baseline median --- Dust $_{\times 1}$ median

- Auto measurements Baseline ensemble

Figure 5. Ensemble snowpack simulations (ESCROC) for locations M1, 2, 3 and F (Fig. 1

b). The grey ensemble is the baseline ensemble, the red ensemble is the ensemble with dust deposition (represented by the vertical bar in the panels). Dashed lines correspond to the ensemble medians. Snow depth measurements are shown in black: crosses for manual measurements and dots for measurements performed with a sonic ranger (see Section 2.1). 


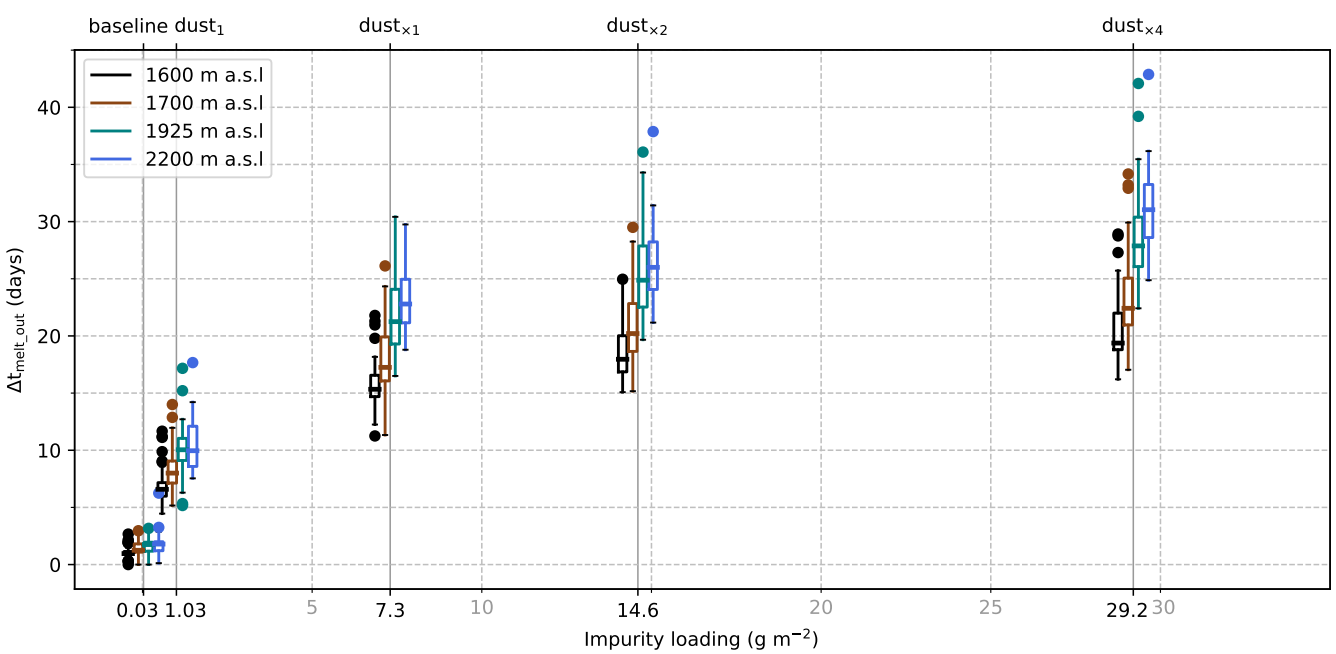

Figure 6. $\Delta t_{\text {melt_out }}$ between the different configurations (dust loading) and the pure snow scenario as a function of LAP mass in the snow pack. The color represents the elevation and the box-plots correspond to the different members of the ensemble. The dots are outliers, defined as data greater than $Q 3+1.5 I Q R$ or lower than $Q 1-1.5 I Q R$ where $Q 1$ and $Q 3$ are respectively the first and third quartile (box) and $I Q R$ is the interqurntile range $(Q 3-Q 1)$.

\subsection{Dust surface radiative effect}

The daily SRE due to LAP in the baseline configuration ranges between 0.01 and $4 \mathrm{~W} \mathrm{~m}^{-2}$ (Fig. 8). For the dust $\times 1$ configuration, the median daily SRE ranges between 0.3 and $80 \mathrm{~W} \mathrm{~m}^{-2}$ (Fig. 8). The daily SRE values exhibit a strong temporal variability, smaller values being found just after the snowfalls and larger values after a long period without snowfall when the snow surface layer is progressively enriched in dust due to melting or sublimation. Some dates (e.g. 7 April for location M3, Fig. 8c) exhibit large spread $\left(\sigma= \pm 30 \mathrm{~W} \mathrm{~m}^{-2}\right)$ in SRE value. This spread corresponds to the shift of the outcropping date of the dust layer between the different members of the ensemble.

Fig. 8e compares the different terms of the daily surface energy balance (SEB, i.e sum of the radiative budget and the turbulent fluxes) for the four locations on average between the date of the dust event and $t_{\text {ground }}$ for each location. It shows that the total SEB is higher for simulations including the dust event and that the difference in total SEB can be mainly attributed to difference in the shortwave net radiation. Median daily SRE due to the dust event ranges between 28 and $35 \mathrm{~W} \mathrm{~m}^{-2}$. Total SEB and all 

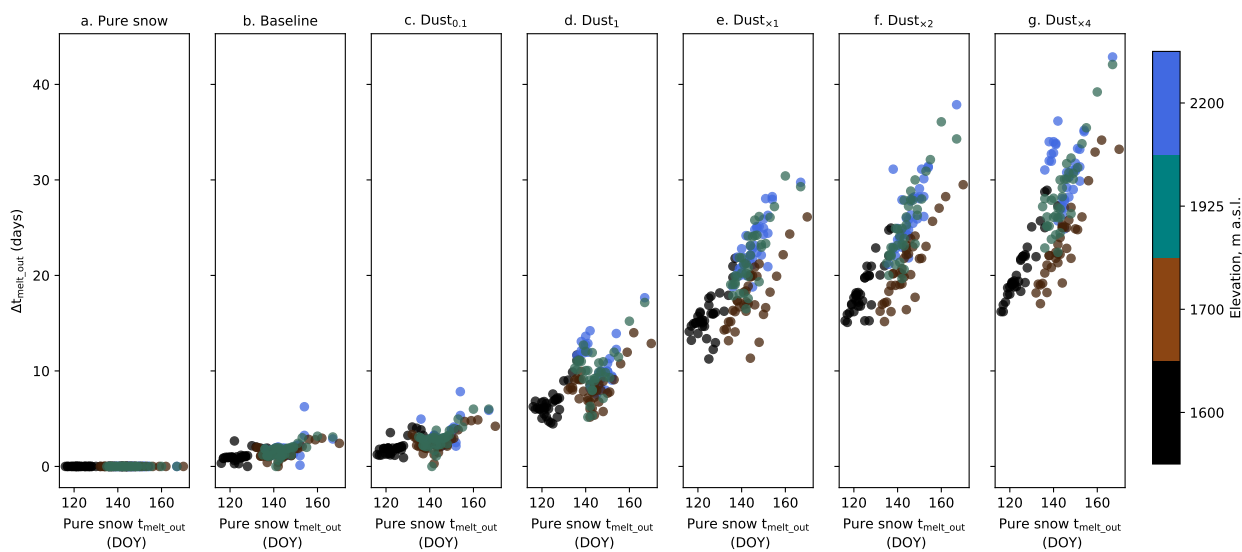

Figure 7. Shortening of the snow season, with respect to the pure snow simulations as a function of the melt-out date of the pure snow simulations. The panels correspond to the model configurations: baseline, dust ${ }_{0.1}$, dust $_{1}$, dust $_{\times 1}$, dust $\times 2$ and dust ${ }_{\times 4}$. The different colors corresponds to the elevation of the locations.

the different fluxes vary with the elevation of the location. Total SEB is decreasing with the elevation because lower temperatures induce lower longwave net radiation and lower sensible and latent heat fluxes. On the contrary, the net shortwave radiation is increasing with the elevation and peak SWE. This is because snow melts later at higher elevation and the incoming solar radiation is increasing with the day of year during spring months. As a consequence, the impact of dust deposition on snow melt is generally increasing with elevation and peak SWE values [Painter et al., 2007]. This is also shown by Fig. 7 where the timing of the pure snow configuration melt-out is controlled by the peak SWE and by the elevation. 

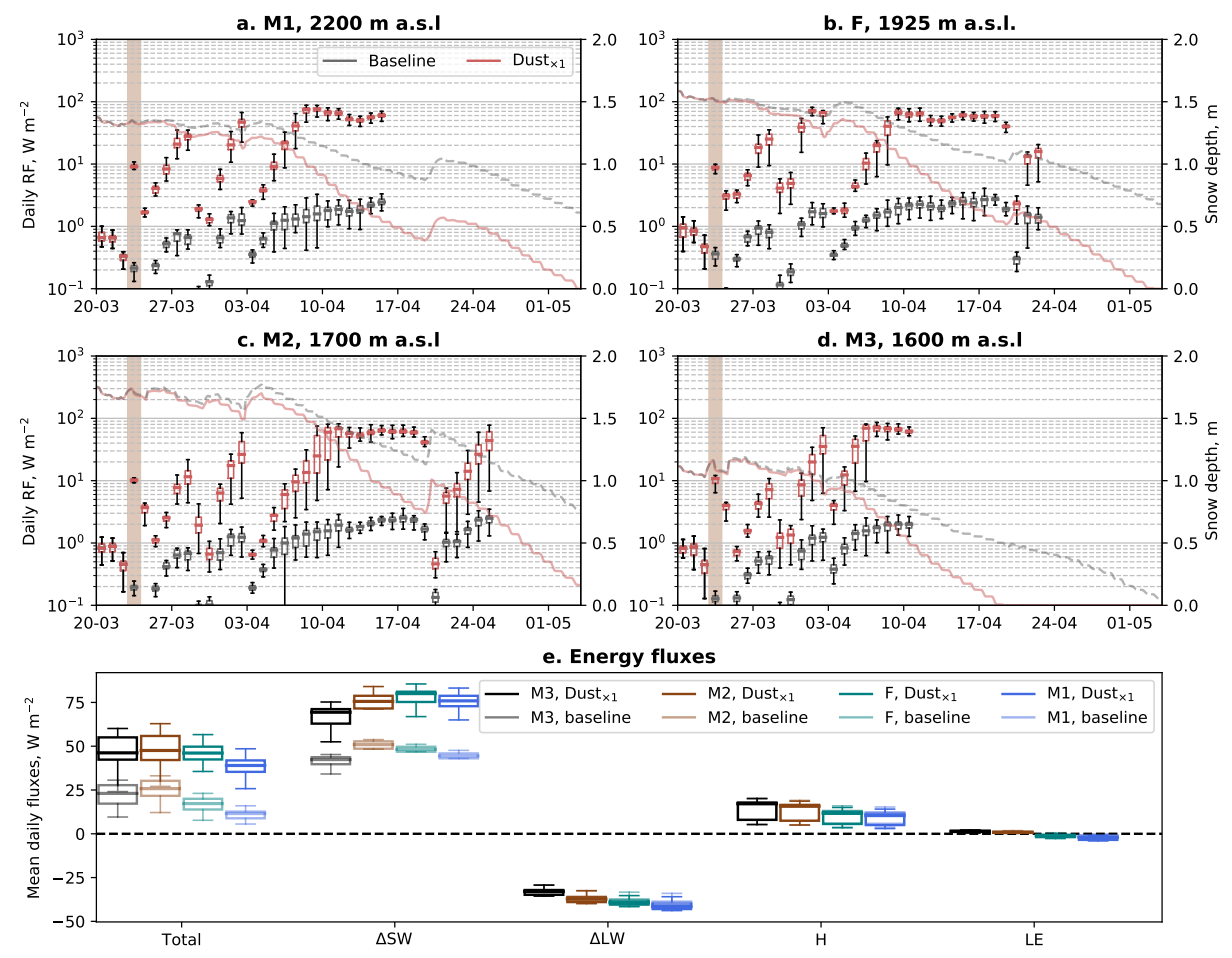

Figure 8. (a,b,c,d) Median simulated snow depth and daily surface radiative effect (SRE) in $\mathrm{W} \mathrm{m} \mathrm{m}^{-2}$ for the dust $_{\times 1}$ scenario (grey lines for the baseline set-up) for each location. The dust deposition event is represented by the red vertical bar. Daily SRE is computed until $t_{\text {ground }}$ for each location and is represented by the box-plots. Median simulated snow depths are the shaded grey dotted and solid red lines. (e) Daily simulated surface energy balance fluxes in $\mathrm{W} \mathrm{m}^{-2}$ averaged from the date of the dust event to $t_{\text {ground }}$ for each location. The transparent box-plots are for the baseline set-up and the plain box-plots for the dust $x_{1}$ scenario. The $\mathrm{x}$-axis shows the different fluxes : total surface energy balance, Shortwave net radiation $(\Delta S W)$, longwave net radiation $(\Delta L W)$, sensible heat flux $(\mathrm{H})$ and latent heat flux (LE). 


\section{Discussion}

We used S2 imagery to retrieve the dust concentration at the snow surface after a dust deposition event. We combined these data with ensemble detailed snowpack simulations in order to calculate the shift in the snow melt-out date due to the dust event.

The daily SRE values simulated in the baseline configuration are in line with the spring SRE order of magnitude reported for Eurasia in Skiles et al. [2018]. The maximum daily SRE in spring in the dust configurations are also of comparable order of magnitude to the maximum daily SRE reported in Skiles et al. [2018] for Europe, Sierra Nevada, USA, and the Rockies, USA, and also measured in the upper Colorado river basin, USA, after several dust deposition events [Painter et al., 2007; Skiles et al., 2012]. For similar dust content, the simulated shortening of the snow cover duration ranges between 20 and 35 days in Skiles et al. [2012] in accordance with the values simulated in this study. To this aim, they used a less detailed snow model but forced by measured SRE. For a given dust amount, Skiles et al. [2012] found larger shortening of the snow cover duration for low elevation which is apparently in contradiction with the results presented here. These results are most probably explained by the fact that their higher elevation sites have lower peak SWE values which is not the case in the present study. We showed here that the impact of the dust event on the shortening of the snow cover duration is determined by the duration of the snow cover on the ground (without the dust event) which is mainly controlled by peak SWE values and by the elevation.

This study also demonstrates that the choice of the snow model largely impacts the computation of the surface energy balance and in turn, the shortening of the snow cover duration. Skiles and Painter [2019] already showed that the shortening can vary from 49 to 20 days when comparing a simple snow model with a detailed one. Here we show that the snow model set-up (depicted here by the spread of the ensemble) can lead to variations between 22 and 42 days for a given location and dust loading. The presence of LAPs, here dust, in the snowpack indeed triggers several feedbacks which are more or less powerful according to the physical laws and parameterizations chosen in the snow model. These feedbacks and the subsequent spread are increasing with the length of the snow cover duration, mainly driven by the peak SWE value and by the elevation. However, despite the uncertainties of this quantification, the multiphysics framework demon- 
strates that the shortening due to dust is higher than the uncertainty range coming from other processes.

Dust content retrieved from satellite data can be reconciled with simulated values but it must be underlined that both are quite uncertain. First, as explained in Warren [2013], retrieving impurity content from satellite is challenging. However the fact that the dust content is particularly high here makes the retrieval more reliable. Second, the surface dust content in the model is dependent on the layering due to the model structure which may lead to slight non-physical variations with the dynamical layering of the dust surface content and SRE. Third, both are affected by the choice of the dust spectral complex refractive index which can vary considerably with the origin region of the dust [Caponi et al., 2017]. However, as hypothesised in Skiles et al. [2012], we showed that the sensitivity of the shortening to the dust mass is higher for low dust content than for high dust content. This relationship between shortening and dust mass is however neither linear nor logarithmic. For a given dust mass, the shortening of the snow cover duration is difficult to predict without a detailed snowpack model quantifying the different feedbacks between LAP and snow cover evolution.

\section{Conclusion}

We have shown that S2 imagery can be used with a simple retrieval method to monitor the evolution of the dust content at the snow surface, provided that there is a clear sky/clean snow image before the event and that the dust mass deposited onto the snow surface is large enough to be detected via satellite (see e.g. Warren, 2013 for detection threshold of impurity content). Such data combined with detailed snowpack modeling and atmospheric reanalysis can be used to estimate the shortening of the snow cover duration due to dust deposition. Here, we show that the dust event from March 2018 may have shortened the snow cover duration by 12 to 30 days depending on elevation and accumulation, with spring averaged daily $\mathrm{SRE}$ reaching almost $35 \mathrm{~W} \mathrm{~m}^{-2}$. We also demonstrated that the longer the snow cover duration, the higher the shortening due to the dust event. In other words, higher elevations and locations with higher peak SWE are more impacted by dust deposition events. In addition, the choice of a snow model is crucial for the accuracy of the SRE and shortening calculation, leading to large uncertainties in these values if computed in a deterministic framework. Last but not least, since the simulations used here relies on atmospheric reanalysis and on Sentinel-2 data which are 
both globally and freely available, such calculation could be easily extended to other locations and other periods provided that dust events are significant enough to be detected by satellite and that the topographic effects could be corrected on the satellite data with a clear sky/clean snow image. In situ measurements of impurity content are also crucial to evaluate the accuracy of the retrieval from satellite data. The results of this study are particularly important for projection of the impacts of climate change on the ski resorts of Krasnaya Polyana as it has already been shown that the snow duration is shortening in this region and dust may have played a significant role in this process. Increasing dust deposition trends had indeed been recorded in this part of the world, [e.g. Kutuzov et al., 2019], fostering the need for detailed impact studies of dust on snow deposition in a changing climate.

\section{Acknowledgments}

CNRM/CEN and IGE are part of Labex OSUG@2020 (Investissements d'Avenir, grant agreement ANR-10-LABX-0056). M.D work was funded by the French National Research Agency (ANR JCJC EBONI grant number ANR-16-CE01-006). M.D., F.T and G.P. was funded by CNES APR MIOSOTIS. We are grateful to Avalanche service of the Gornaya Karusel ski resort and to Maxim Pankov personally for providing snow depth measurement data. We also thank Andrey Tsibirov for sample collection. Research of the dust deposition in Caucasus was funded by the RSF project 17-17-01270. Sample collection and analysis were funded by the President Grant for Government Support of Young Russian Scientists MK -2508.2017.5. S.G. was supported by the Centre national d'Etudes Spatiales (CNES/TOSCA). Dr. Painter's work was funded by NASA project NNX10AO97G.

S2 reflectances and impurity maps and snow depth measurements are available at http://doi.org/10.5281/zenodo.4014726. The code used in this study was developed inside the open source SURFEX project (http://www.umr-cnrm.fr/surfex). While it is not yet implemented in an official SURFEX release, the code will be downloadable from a specific tag of the git repository maintained by Centre d'Études de la Neige upon publication of the paper. The full procedure and documentation to access this git repository can be found at : https://opensource.cnrm-game-meteo.fr/projects/snowtools_git/wiki. Tartes model is available here : http://snowtartes.pythonanywhere.com/ (web application and python module downlaod). 


\section{References}

Beniston, M., D. Farinotti, M. Stoffel, L. M. Andreassen, E. Coppola, N. Eckert, A. Fantini, F. Giacona, C. Hauck, M. Huss, H. Huwald, M. Lehning, J.-I. López-Moreno, J. Magnusson, C. Marty, E. Morán-Tejéda, S. Morin, M. Naaim, A. Provenzale, A. Rabatel, D. Six, J. Stötter, U. Strasser, S. Terzago, and C. Vincent (2018), The european mountain cryosphere: a review of its current state, trends, and future challenges, The Cryosphere, 12(2), 759-794, doi: 10.5194/tc-12-759-2018.

Blankinship, J. C., M. W. Meadows, R. G. Lucas, and S. C. Hart (2014), Snowmelt timing alters shallow but not deep soil moisture in the sierra nevada, Water Resources Research, 50(2), 1448-1456, doi:10.1002/2013WR014541.

Brun, E., P. David, M. Sudul, and G. Brunot (1992), A numerical model to simulate snow-cover stratigraphy for operational avalanche forecasting, J. Glaciol., 38(128), $13-22$

Caponi, L., P. Formenti, D. Massabo, C. D. Biagio, M. Cazaunau, E. Pangui, S. Chevaillier, G. Landrot, M. O. Andreae, K. Kandler, et al. (2017), Spectraland size-resolved mass absorption efficiency of mineral dust aerosols in the shortwave spectrum: a simulation chamber study, Atmospheric Chemistry and Physics, $17(11), 7175-7191$.

Di Mauro, B., F. Fava, L. Ferrero, R. Garzonio, G. Baccolo, B. Delmonte, and R. Colombo (2015), Mineral dust impact on snow radiative properties in the european alps combining ground, uav, and satellite observations, Journal of Geophysical Research: Atmospheres, 120(12), 6080-6097, doi:10.1002/2015JD023287.

Di Mauro, B., G. Baccolo, R. Garzonio, C. Giardino, D. Massabò, A. Piazzalunga, M. Rossini, and R. Colombo (2017), Impact of impurities and cryoconite on the optical properties of the morteratsch glacier (swiss alps), The Cryosphere, 11(6), 2393-2409, doi:10.5194/tc-11-2393-2017.

Di Mauro, B., R. Garzonio, M. Rossini, G. Filippa, P. Pogliotti, M. Galvagno, U. Morra di Cella, M. Migliavacca, G. Baccolo, M. Clemenza, B. Delmonte, V. Maggi, M. Dumont, F. Tuzet, M. Lafaysse, S. Morin, E. Cremonese, and R. Colombo (2019), Saharan dust events in the european alps: role in snowmelt and geochemical characterization, The Cryosphere, 13(4), 1147-1165, doi: 10.5194/tc-13-1147-2019. 
Dumont, M., E. Brun, G. Picard, M. Michou, Q. Libois, J. Petit, M. Geyer, S. Morin, and B. Josse (2014), Contribution of light-absorbing impurities in snow to greenland/'s darkening since 2009, Nature Geoscience, 7(7), 509-512, doi:10.1038/ngeo2180.

Dumont, M., L. Arnaud, G. Picard, Q. Libois, Y. Lejeune, P. Nabat, D. Voisin, and S. Morin (2017), In situ continuous visible and near-infrared spectroscopy of an alpine snowpack, The Cryosphere, 11(3), 1091-1110, doi:10.5194/tc-11-1091-2017.

Flanner, M. G. (2013), Arctic climate sensitivity to local black carbon, Journal of Geophysical Research: Atmospheres, 118(4), 1840-1851, doi:10.1002/jgrd.50176.

Gascoin, S., M. Dumont, and G. Picard (2018), Image of the Week - Orange is the new white, https://blogs.egu.eu/divisions/cr/2018/06/15/image-of-the-weekorange-is-the-new-white/.

Gascoin, S., M. Grizonnet, M. Bouchet, G. Salgues, and O. Hagolle (2019), Theia snow collection: high-resolution operational snow cover maps from sentinel-2 and landsat-8 data, Earth System Science Data, 11(2), 493-514, doi: 10.5194/essd-11-493-2019.

Ginot, P., M. Dumont, S. Lim, N. Patris, J.-D. Taupin, P. Wagnon, A. Gilbert, Y. Arnaud, A. Marinoni, P. Bonasoni, and P. Laj (2014), A 10 year record of black carbon and dust from a mera peak ice core (nepal): variability and potential impact on melting of himalayan glaciers, The Cryosphere, 8(4), 1479-1496, doi:10.5194/tc-8-1479-2014.

Hagolle, O., M. Huc, C. Desjardins, S. Auer, and R. Richter (2017), Maja algorithm theoretical basis document, doi:10.5281/zenodo.1209633.

Huovinen, P., J. Ramírez, and I. Gómez (2018), Remote sensing of albedo-reducing snow algae and impurities in the maritime antarctica, ISPRS Journal of Photogrammetry and Remote Sensing, 146, 507 - 517, doi:https://doi.org/10.1016/j. isprsjprs.2018.10.015.

IPCC (2013), Summary for Policymakers, book section SPM, p. 1-30, Cambridge University Press, Cambridge, United Kingdom and New York, NY, USA, doi: 10.1017/CBO9781107415324.004.

Kokhanovsky, A., M. Lamare, B. Di Mauro, G. Picard, L. Arnaud, M. Dumont, F. Tuzet, C. Brockmann, and J. E. Box (2018), On the reflectance spectroscopy of snow, The Cryosphere, 12(7), 2371-2382, doi:10.5194/tc-12-2371-2018. 
Kokhanovsky, A., M. Lamare, O. Danne, C. Brockmann, M. Dumont, G. Picard, L. Arnaud, V. Favier, B. Jourdain, E. Le Meur, et al. (2019), Retrieval of snow properties from the sentinel-3 ocean and land colour instrument, Remote Sensing, $11(19), 2280$.

Kokkalis, P., R. Mamouri, M. Todua, G. Didebulidze, A. Papayannis, V. Amiridis, S. Basart, C. Pérez, and J. Baldasano (2012), Ground-, satellite-and simulationbased analysis of a strong dust event over abastumani, georgia, during may 2009, International journal of remote sensing, 33(16), 4886-4901.

Krinner, G., C. Derksen, R. Essery, M. Flanner, S. Hagemann, M. Clark, A. Hall, H. Rott, C. Brutel-Vuilmet, H. Kim, C. B. Ménard, L. Mudryk, C. Thackeray, L. Wang, G. Arduini, G. Balsamo, P. Bartlett, J. Boike, A. Boone, F. Chéruy, J. Colin, M. Cuntz, Y. Dai, B. Decharme, J. Derry, A. Ducharne, E. Dutra, X. Fang, C. Fierz, J. Ghattas, Y. Gusev, V. Haverd, A. Kontu, M. Lafaysse, R. Law, D. Lawrence, W. Li, T. Marke, D. Marks, O. Nasonova, T. Nitta, M. Niwano, J. Pomeroy, M. S. Raleigh, G. Schaedler, V. Semenov, T. Smirnova, T. Stacke, U. Strasser, S. Svenson, D. Turkov, T. Wang, N. Wever, H. Yuan, and W. Zhou (2018), Esm-snowmip: Assessing models and quantifying snow-related climate feedbacks, Geoscientific Model Development Discussions, 2018, 1-32, doi:10.5194/gmd-2018-153.

Kutuzov, S., M. Shahgedanova, V. Mikhalenko, P. Ginot, I. Lavrentiev, and S. Kemp (2013), High-resolution provenance of desert dust deposited on mt. elbrus, caucasus in 2009-2012 using snow pit and firn core records, The Cryosphere, 7(5), 1481-1498, doi:10.5194/tc-7-1481-2013.

Kutuzov, S., M. Legrand, S. Preunkert, P. Ginot, V. Mikhalenko, K. Shukurov, A. Poliukhov, and P. Toropov (2019), History of desert dust deposition recorded in the elbrus ice core, Atmospheric Chemistry and Physics Discussions, 2019, 1-26, doi:10.5194/acp-2019-411.

Lafaysse, M., B. Cluzet, M. Dumont, Y. Lejeune, V. Vionnet, and S. Morin (2017), A multiphysical ensemble system of numerical snow modelling, The Cryosphere, 11, 1173-1198, doi:10.5194/tc-11-1173-2017.

Libois, Q., G. Picard, J. L. France, L. Arnaud, D. Dumont, C. M. Carmagnola, and M. D. King (2013), Influence of grain shape on light penetration in snow, The Cryosphere, 7, 1803-1818, doi:10.5194/tc-7-1803-2013. 
Marmureanu, L., C. A. Marin, S. Andrei, B. Antonescu, D. Ene, M. Boldeanu, J. Vasilescu, C. Viţelaru, O. Cadar, and E. Levei (2019), Orange snow-a saharan dust intrusion over romania during winter conditions, Remote Sensing, 11(21), doi:10.3390/rs11212466.

Moosmuller, H., J. P. Engelbrecht, M. Skiba, G. Frey, R. K. Chakrabarty, and W. P. Arnott (2012), Single scattering albedo of fine mineral dust aerosols controlled by iron concentration, Journal of Geophysical Research: Atmospheres, 117(D11), doi:10.1029/2011JD016909.

Mudryk, L. R., C. Derksen, S. Howell, F. Laliberté, C. Thackeray, R. SospedraAlfonso, V. Vionnet, P. J. Kushner, and R. Brown (2018), Canadian snow and sea ice: historical trends and projections, The Cryosphere, 12(4), 1157-1176, doi:10.5194/tc-12-1157-2018.

Nastos, P., N. Kampanis, K. Giaouzaki, and A. Matzarakis (2011), Environmental impacts on human health during a saharan dust episode at crete island, greece, Meteorologische Zeitschrift, 20(5), 517-529.

Painter, T. H., N. P. Molotch, M. P. Cassidy, M. G. Flanner, and K. Steffen (2007), Contact spectroscopy for the determination of stratigraphy of snow grain size, $J$. Glaciol., 53, 121-127, doi:10.3189/172756507781833947.

Painter, T. H., J. S. Deems, J. Belnap, A. F. Hamlet, C. C. Landry, and B. Udall (2010), Response of colorado river runoff to dust radiative forcing in snow, Proc. Natl. Acad. Sci., doi:10.1073/pnas.0913139107.

Painter, T. H., A. C. Bryant, and S. McKenzie Skiles (2012), Radiative forcing by light absorbing impurities in snow from modis surface reflectance data, Geophysical Research Letters, 39, L17,502, doi:10.1029/2012GL052457.

Picard, G., M. Dumont, M. Lamare, F. Tuzet, F. Larue, R. Pirazzini, and L. Arnaud (2020), Spectral albedo measurements over snow-covered slopes: theory and slope effect corrections, The Cryosphere, 14(5), 1497-1517, doi:10.5194/tc-14-1497-2020.

Roesli, h. P., and C. Karvelis (2018), Long-range dust outbreak over africa and greece, https://www.eumetsat.int/website/home/Images/ImageLibrary/DAT_3902461.html.

Salomonson, V., and I. Appel (2004), Estimating fractional snow cover from modis using the normalized difference snow index, Remote Sensing of Environment, 89(3), 351 - 360, doi:https://doi.org/10.1016/j.rse.2003.10.016. 
Shahgedanova, M., S. Kutuzov, K. H. White, and G. Nosenko (2013), Using the significant dust deposition event on the glaciers of mt. elbrus, caucasus mountains, russia on 5 may 2009 to develop a method for dating and "provenancing" of desert dust events recorded in snow pack, Atmospheric Chemistry and Physics, 13(4), 1797-1808, doi:10.5194/acp-13-1797-2013.

Skiles, M. S., and T. H. Painter (2018), Assessment of radiative forcing by lightabsorbing particles in snow from in situ observations with radiative transfer modeling, Journal of Hydrometeorology, 19(8), 1397-1409.

Skiles, M. S., M. Flanner, K. Cook, M. Dumont, and T. Painter (2018), Radiative forcing by light-absorbing particles in snow, Nature Climate Change, 8(11), 964971, doi:10.1038/s41558-018-0296-5.

Skiles, S. M., and T. H. Painter (2019), Toward understanding direct absorption and grain size feedbacks by dust radiative forcing in snow with coupled snow physical and radiative transfer modeling, Water Resources Research, 55(8), 7362-7378, doi:10.1029/2018WR024573.

Skiles, S. M., T. H. Painter, J. S. Deems, A. C. Bryant, and C. C. Landry (2012), Dust radiative forcing in snow of the upper colorado river basin: 2. interannual variability in radiative forcing and snowmelt rates, Water Resources Research, 48(7), doi:10.1029/2012WR011986.

Sokratov, S. A., Seliverstov, Y. G., and A. Shnyparkov (2014), Assessment of the economic risk for the ski resorts of changes in snow cover duration, Ice Snow, 54(3), 100-106, doi:10.15356/2076-6734-2014-3-100-106.

Solomos, S., N. Kalivitis, N. Mihalopoulos, V. Amiridis, G. Kouvarakis, A. Gkikas, I. Binietoglou, A. Tsekeri, S. Kazadzis, M. Kottas, Y. Pradhan, E. Proestakis, P. T. Nastos, and F. Marenco (2018), From tropospheric folding to khamsin and foehn winds: How atmospheric dynamics advanced a record-breaking dust episode in crete, Atmosphere, 9(7), doi:10.3390/atmos9070240.

Sterle, K. M., J. R. McConnell, J. Dozier, R. Edwards, and M. G. Flanner (2013), Retention and radiative forcing of black carbon in eastern sierra nevada snow, The Cryosphere, 7(1), 365-374, doi:10.5194/tc-7-365-2013.

Tuzet, F., M. Dumont, M. Lafaysse, G. Picard, L. Arnaud, D. Voisin, Y. Lejeune, L. Charrois, P. Nabat, and S. Morin (2017), A multilayer physically based snowpack model simulating direct and indirect radiative impacts of light-absorbing im- 
purities in snow, The Cryosphere, 11(6), 2633-2653, doi:10.5194/tc-11-2633-2017.

Vionnet, V., E. Brun, S. Morin, A. Boone, E. Martin, S. Faroux, P. L. Moigne, and J.-M. Willemet (2012), The detailed snowpack scheme Crocus and its implementation in SURFEX v7.2, Geosci. Model. Dev., 5, 773-791, doi: 10.5194/gmd-5-773-2012.

Warren, S. G. (2013), Can black carbon in snow be detected by remote sensing?, Journal of Geophysical Research: Atmospheres, 118(2), 779-786, doi: 10.1029/2012JD018476.

Warren, S. G., and W. Wiscombe (1980), A model for the spectral albedo of snow. ii: Snow containing atmospheric aerosols, J. Atmos. Sci., 37, 2734-2745. 